\title{
CONSTITUIÇÃO DE CARREIRAS INEXISTENTES, UMA LEITURA A PARTIR DE MAX WEBER
}

\author{
CONSTITUCIÓN DE CARRERAS EN CARRERAS INEXISTENTES: UNA LECTURA A \\ PARTIR DE MAX WEBER
}

\author{
CONSTITUTION OF CAREERS IN UNEXISTENT CAREERS: A READING FROM \\ MAX WEBER
}

Renata Riva FINATTI ${ }^{1}$

\begin{abstract}
RESUMO: $\mathrm{O}$ artigo discute, à luz dos conceitos de ação social, burocracia, poder e dominação, de Max Weber, a constituição da "carreira de direção escolar" em escolas públicas de Curitiba/PR. O termo foi cunhado a partir da pesquisa sobre a escolha, por meio de consulta à comunidade escolar, das funções de direção e vice-direção das escolas. Constatou-se, a partir do resultado dos pleitos ocorridos desde 1983, que um grupo de profissionais, concursados para a docência no município, constituiu suas carreiras em função distinta àquela dos concursos que prestaram: a função diretiva das escolas. Uma vez eleitos, muitos no primeiro pleito ocorrido no Município, no início dos anos 1980, só saíram da função de direção para aposentar-se.
\end{abstract}

PALAVRAS-CHAVE: Direção escolar. Democracia. Escolha de diretores. Escola pública.

RESUMEN: El artículo discute, a la luz de los conceptos de acción social, burocracia, poder y dominación, de Max Weber, la constitución de la "carrera de dirección escolar" en escuelas públicas de Curitiba. La expresión, inexistente en el Ayuntamiento Municipal de Curitiba, fue acuñada a partir de la investigación sobre la elección, por medio de consulta a la comunidad escolar, de las funciones de dirección de estas escuelas. Se constató, a partir de una serie histórica construida con el resultado de los pleitos ocurridos desde 1983, que un grupo de profesionales de la educación, concursados para la docencia en el municipio, constituyó sus carreras en función distinta a la de los concursos que prestaron: en la función directiva de las escuelas. Una vez elegidos, sólo salieron de la función de dirección para jubilarse.

PALABRAS CLAVE: Dirección escolar. Democracia. Elección de diretores. Escuela pública.

ABSTRACT: The article discusses, in the light of Max Weber 's concepts of social action, bureaucracy, power and domination, the constitution of the "school management career" in public schools in Curitiba/PR. The expression was coined from the research about the choice, through consultation to the school community, of the management functions of these schools. It was verified, from the result of the disputes occurred since 1983, that a group of professionals, who had been admitted to teaching in the municipality, constituted their careers in a distinct function from that they were admitted in: the direction. Once elected, many in the first election

${ }^{1}$ Universidade Federal do Paraná (UFPR), Curitiba - PR - Brasil. Doutoranda no Programa de Pós-Graduação em Educação. ORCID: https://orcid.org/0000-0002-6543-0066. E-mail: rrfinatti@gmail.com

RPGE- Revista on line de Política e Gestão Educacional, Araraquara, v. 24, n. 3, p. 1445-1460, set./dez. 2020. e-ISSN:1519-9029 
process to school management in the Municipality in the early 1980s, only left the function to retire.

KEYWORDS: School direction. Democracy. Director's election. Public school.

\section{Introdução}

$\S 16$. Poder significa la probabilidad de imponer la propia voluntad, dentro de una relación social, aun contra toda resistencia y cualquiera que sea el fundamento de esa probabilidad.

Por dominación debe entenderse la probabilidad de encontrar obediencia a un mandato de determinado contenido entre personas dadas; por disciplina debe entenderse la probabilidad de encontrar obediencia para un mandato por parte de un conjunto de personas que, en virtud de actitudes arraigadas, sea pronta, simple y automática.

1. El concepto de poder es sociológicamente amorfo. Todas las cualidades imaginables de un hombre y toda suerte de constelaciones posibles pueden colocar a alguien en la posición de imponer su voluntad en una situación dada. El concepto de dominación tiene, por eso, que ser más preciso y solo puede significar la probabilidad de que un mandato sea obedecido.

2. El concepto de disciplina encierra el de una "obediencia habitual" por parte de las masas sin resistencia ni crítica (WEBER, 2002, p. 43).

A dominação é um caso especial de poder. Os conceitos acima, de antemão, nos ajudam a entender um pouco as relações que se impõe nos grupos que constituem a instituição escolar pública. Junto aos conceitos, precisamos pensar a preocupação não com quem impõe o poder ou é o dominador, mas com o outro, com o porquê do outro obedecer a tal imposição e ser dominado.

Neste fato talvez esteja a grande questão que se tentará desenhar: como e por que as comunidades escolares elegem, seguidamente, a(o) mesma(o) profissional da educação para um cargo que deveria ter por natureza a rotatividade - por isso seu provimento pensado como consulta à comunidade? Será que alguns serão sempre dominados e outros dominadores?

A cultura escolar está permeada por relações políticas e, consequentemente, pelo exercício de poder e da dominação. Em essência, isso se dá porque não é a escola uma instituição isolada da sociedade, mas porque nela se reproduzem ações dessa sociedade. Até mesmo em processos "democráticos", como deveriam se constituir as consultas à comunidade escolar para escolha de dirigentes escolares, foi constatado em pesquisa anterior desta autora a constituição de "carreiras em carreiras inexistentes"2", por meio da manutenção do poder em uma função que tem, por natureza e forma de provimento, a rotatividade como característica

${ }^{2}$ Expressão indicada pela $\operatorname{Prof}^{\mathrm{a}} \operatorname{Dr}^{\mathrm{a}}$ Teise de Oliveira Guaranha Garcia durante o exame de qualificação da referida pesquisa, imediatamente incorporada à dissertação por retratar o que se desenhou na pesquisa.

RPGE- Revista on line de Política e Gestão Educacional, Araraquara, v. 24, n. 3, p. 1445-1460, set./dez. 2020. e-ISSN:1519-9029 
(FINATTI, 2016). A pesquisa, intitulada "Eleições como forma de provimento da Direção Escolar na Rede Municipal de Ensino de Curitiba", analisou os processos de consulta à comunidade escolar "como forma de provimento da direção escolar nas escolas públicas do município de Curitiba/PR, considerando as possibilidades e limites deste instrumento - eleição - como ferramenta de gestão democrática da escola pública” (FINATTI, 2016, p. 16). O processo é regulamentado no referido município desde 1983, quando ocorreu o primeiro pleito cujo mandato iniciou-se em janeiro de 1984.

As análises desenvolvidas explicitam que, dentre os(as) profissionais da educação que, entre 1984 e 2016, se elegeram para compor a equipe diretiva de escolas municipais, apenas $43,77 \%$ ficaram um mandato (três anos) no poder, enquanto que aproximadamente $13 \%$ ficaram mais de dez anos nesta função, chegando a 25 anos. A respeito destes é que se pode afirmar que constituíram uma carreira em uma carreira inexistente, uma vez que no município de Curitiba não há uma carreira para "direção de escola" e a carreira do magistério poderia ser concluída, até 2016, com 25 anos de contribuição. Ou seja, tais pessoas, formadas e concursadas para atuarem como docentes nas escolas do município, passaram toda a sua carreira em uma função distinta, a diretiva. Legalmente, isso foi possível porquanto havia uma brecha, na legislação sobre "eleições" para a equipe diretiva das escolas anterior a 2014, que permitia a reeleição; no entanto, foi também possível pelas circunstâncias envolvidas na assumpção à figura de mando da equipe diretiva.

Como afirmado, poder e dominação, enquanto conceitos Weberianos, são resultados da ação social, da relação entre diferentes sujeitos. O poder envolve imposição da vontade pessoal de A sobre B; relaciona-se, portanto, ao uso da força, além das fontes de legitimação. Os acordos de sociabilidade são positivados pelo direito, que legitimam as ações e sustentam que aquilo que é feito para cada um(a) tem razão por ser para todos(as). O direito, assim, é importante pelo formalismo a ele intrínseco.

A eleição para compor as equipes diretivas das escolas se constitui instrumento democrático. Não obstante, a democracia não existirá sem a burocracia e, quem a domina - a burocracia - passa a dominar também os meios democráticos e a discursar com legitimidade. Todos(as) os(as) profissionais, ao serem aprovados em concurso, demonstram conhecimentos acerca do magistério. Entretanto, quando um(a) deles(as) começa a exercer a função de diretor(a), passa por uma série de experiências, participa de cursos sobre aspectos específicos da administração, além de estar presente às reuniões na Secretaria de Educação e órgão afins, que lhe proporcionam conhecimentos que os(as) demais profissionais não possuem. Este fato os(as) coloca em situação especial, pois passam a dominar o que outros não sabem e, em boa 
parte dos casos, não conseguem, ou não querem compartilhar, aquilo que lhes dá poder. Os(as) demais, por seu lado, muitas vezes se sentem intimidados por não possuírem as informações e a experiência do(a) diretor(a) em exercício e acabam por não disputar a função. Este conhecimento, das regras do jogo, lhes permite exercer dominação racional-legal, cujo tipo mais puro seria a burocracia, o domínio da lei para a qual submetem-se todos.

Qualquer que seja a instituição dita democrática, haverá, nas relações entre os sujeitos desta instituição, a disputa pelo poder de tomar decisões. Nos espaços democráticos em que os consensos tentarão ser construídos a partir da argumentação das distintas partes, a opinião ou percepção dos sujeitos só entrará em pauta se for colocada em disputa. Natural será, nesse processo, que aqueles que dominam a burocracia e tem um poder legitimado, terão maior e mais fácil influência sobre a opinião dos demais. É preciso destacar que a disputa pelo poder envolve a disputa pela posse de fontes de legitimação.

\section{Ação social, burocracia, poder e dominação em Max Weber: a "eleição" para direção sob os conceitos weberianos}

Max Weber, em suas análises sociológicas, foca nos indivíduos, e, portanto, na ação social:

$\S$ 1. Concepto de la sociología y del "significado" em la acción social. Debe entender-se entenderse por sociología [...]: una ciencia que pretende entender, interpretándola, la acción social para de esa manera explicarla causalmente en su desarrollo y efectos. [...] La "acción social", por tanto, es una acción en donde el sentido mentado por su sujeto o sujetos está referido a la conducta de otros, orientándose por ésta en su desarrollo (WEBER, 2002, p. 5).

A ação social e a relação social orientam-se pela existência de uma ordem legítima, que pode se dar de forma afetiva ou sentimental; ligada à tradição, do que sempre existiu daquela determinada maneira; racional vinculada à valores; e em virtude de estatutos positivados, na legalidade (WEBER, 2002, p. 27-30). Ação social é a conduta humana dotada de sentido, justificativa elaborada pelo autor da ação, conduta humana com significado subjetivo dado por quem a executa.

Nada, no entanto, é consolidado fora dos indivíduos, segundo Weber. Seu personagem coletivo compõe um aglomerado de pessoas, não havendo uma racionalidade única. A análise de Max Weber é sempre constituída de sentido, partindo do material, real.

Da mesma forma, os tipos ideais por ele descritos racionalmente são pontos fixos construídos a partir da materialidade, a fim de melhor conhecê-la e explicá-la. As formações 
sociais "no son otra cosa que desarrollos y entrelazamientos de acciones específicas de personas individuales" (WEBER, 2002, p. 12). Ao ler seus escritos, percebe-se que a espinha dorsal de seus conceitos é recheada de empiria, da análise concreta de cada situação, tendo como ponto de partida os sujeitos. Assim, o autor constrói os tipos ideais, a partir da realidade observada e da sucessão dos acontecimentos, não como elementos desejados, mas para serem sobrepostos à realidade, analisando-se o quão distante da realidade descrita estão.

\begin{abstract}
No que se refere à investigação, o conceito do tipo ideal propõe-se formar o juízo de atribuição. Não é uma "hipótese", mas pretende apontar o caminho para a formação de hipóteses. Embora não constitua uma exposição da realidade, pretende conferir a ela meios expressivos unívocos. É, portanto, a "ideia" da organização moderna e historicamente dada da sociedade numa economia de mercado, ideia essa que evolui de acordo com os mesmos princípios lógicos que serviram, por exemplo, para formar a da "economia urbana" da Idade Média à maneira de um conceito "genético". Não é pelo estabelecimento de uma média dos princípios econômicos que realmente existiram em todas as cidades examinadas, mas antes, pela construção de um tipo ideal, que neste último caso se forma o conceito de "economia urbana". Obtém-se um tipo ideal mediante a acentuação unilateral de um ou vários pontos de vista, e mediante o encadeamento de grande quantidade de fenômenos isoladamente dados, difusos e discretos, que se podem dar em maior ou menor número ou mesmo faltar por completo, e que se ordenam segundo os pontos de vista unilateralmente acentuados, a fim de se formar um quadro homogêneo de pensamento. Torna-se impossível encontrar empiricamente na realidade esse quadro, na sua pureza conceitual, pois tratase de uma utopia (WEBER, 2003, p. 106).
\end{abstract}

Os tipos ideais não são conceitos em si, são racionalmente construídos e por isso aproximam-se da "ideia". Os tipos ideais são instrumentais comparativos para buscar explicações, não são pontos seguros para se detectar a realidade, como os conceitos, mas a busca por lógicas e regularidades no interior dos fenômenos, como uma racionalidade interna ao fenômeno observado (WEBER, 2003). Assim, não haverá nos tipos ideais puros correspondentes na realidade concreta, pois eles se darão de forma misturada uma vez que foram construídos a partir das regularidades encontradas na realidade, e não na conceituação da realidade em si. O tipo ideal, é, portanto, um instrumental de categorias criadas a partir da empiria para formular hipóteses sobre determinados fenômenos sociais.

Desta forma, Weber tipifica três formas de dominação, com distintos fundamentos de legitimidade, encontradas a partir da observação das relações humanas: racional-legal, carismática e tradicional. A dominação é, a bem da verdade, um

Estado de cosas por el cual una voluntad manifiesta ("mandato") del "dominador" o de los "dominadores" influye sobre los actos de otros (del "dominado" o de los "dominados"), de tal suerte que em un grado socialmente 
relevante estos actos tienen lugar como si los dominados hubieran adoptado por sí mismos y como máxima de su obrar el contenido del mandato (“obediencia") (WEBER, 2002, p. 699).

Tendo por base o conceito acima, que explicita a ideia de que os dominados agem como se fosse sua a vontade de agir da maneira como os dominadores mandam, podemos tentar descrever brevemente o fundamento de legitimidade de cada uma das formas de dominação.

A dominação racional-legal é expressa, como afirmado, na burocracia como tipo mais puro. Ela é impessoal e universal, sujeita a provas e concursos para testagem; envolve o domínio da lei a que todos os demais estão submetidos. Sua legitimidade fundamenta-se, destarte, "en la creencia en la legalidad de ordenaciones estatuidas y de los derechos de mando de los llamados por esas ordenaciones a ejercer la autoridad (autoridad legal)" (WEBER, 2002, p. 172).

A dominação carismática, em contraponto à supracitada, é personalíssima, pertence ao sujeito e por isso tem caráter extraordinário, com sucessão instável. O fundamento da legitimidade, nesta forma de dominação, "descansa en la entrega extracotidiana a la santidad, heroísmo o ejemplaridad de una persona y a las ordenaciones por ella creadas o reveladas (llamada) (autoridad carismática)" (WEBER, 2002, p. 172). A dominação carismática tem um elemento de fé a ela vinculado, a crença de que aquele sujeito tem algo heroico a ele relacionado. Essa forma de dominação rompe processos lineares com heroísmo, mas, para se manter, precisará da rotinização/cotidianização, tornando-a um processo de racionalização (legalização) ou tradicionalização (WEBER, 2002, p. 197).

A dominação tradicional, por último, seria uma rotinização da dominação carismática. É fundamentada na tradição e, portanto, pode ser "herdada".

[...] una dominación es tradicional cuando su legitimidad descansa em la santidad de ordenaciones y poderes de mando heredados de tiempos lejanos, "desde tiempo inmemorial", creyéndose en ella en méritos de esa santidad. [...] La "asociación de dominación", en el caso más sencillo, es primariamente una "asociación de piedad" determinada por una comunidad de educación (WEBER, 2002, p. 180).

Como afirmado, as formas de dominação tipificadas por Weber não existem materialmente assim como descritas. São tipo ideais que, na realidade objetiva, se misturam. "[...] toda forma típica de dominación en virtud de una constelación de intereses, y sobre todo en virtud de la posesión de un monopolio, puede transformarse gradualmente en una dominación autoritaria" (WEBER, 2002, p. 697). Um sujeito - diretor ou diretora de escola, pode ganhar um primeiro pleito ao qual concorre por exercer uma dominação carismática sobre 
seus eleitores, porém a rotinização dessa dominação originalmente personificada, pode tornarse dominação tradicional. Exceções à parte, observa-se frequentemente que a diretora, uma vez eleita, tem grande possibilidade de tentar a reeleição e de obter sucesso, em boa parte dos casos, sem adversários. Além da insegurança em relação a sua própria competência para exercer uma função apregoada como complexa e inacessível, o medo de enfrentar a direção já estabelecida, perder e enfrentar retaliações faz com que poucas pessoas se arrisquem a entrar na disputa (FINATTI, 2016).

O Estado e a Política não funcionam, a longo prazo, com uma única expressão de dominação tipificada por Max Weber. "O instrumento decisivo da política é a violência" (WEBER, 2011, p. 144), e o Estado é quem detém a violência legítima sobre determinado território. Acrescente-se que muitas vezes a própria administração municipal, quando se mantém no poder, tem interesse em que as pessoas que lhe eram fiéis, permaneçam nos cargos, contribuindo, sempre que podem, para que isso aconteça. No entanto, é impossível também ascender ao poder ou mantê-lo sem o domínio de alguma burocracia, sem o domínio da máquina. Para além disso, quando falamos, por exemplo, na ascensão aos cargos eletivos no País, é preciso conhecer a máquina partidária e, para manter o poder, faz-se necessário manter o controle dos espaços que ajudam a se manter.

O desenvolvimento da racionalidade instrumental no Ocidente, segundo as análises de Max Weber, se impôs com a força de sua eficácia instrumental. A racionalidade permeia todas as áreas da vida. Esta racionalidade é o que poderíamos chamar de busca de meios para chegar a determinados fins. A Burocracia é então entendida por Weber como mecanismo necessário para governar sociedades complexas.

Da mesma forma, na escola. A pessoa que se candidata à função diretiva precisará manter sob seu controle os espaços ou sujeitos dominados que a escolheram. Exemplo disso é a relutância que têm de deixar de ter o controle de tudo o que acontece na escola e em seu entorno, incluindo aí o Conselho de Escola, órgão colegiado que fisscaliza sua função, e do qual, segundo a legislação vigente, a equipe diretiva ainda é membro nato e presidente.

A questão da manutenção do poder também pode ser vista como forte nas instituições escolares de Curitiba ao percebemos a organização do próprio calendário de consultas à comunidade para escolha de equipes diretivas em relação ao calendário de organização dos Concursos internos de remoção. Os processos de remoção anual da Secretaria Municipal da Educação ocorrem, em ano de eleição para equipe diretiva, sempre após as eleições serem realizadas, permitindo que os perdedores insatisfeitos, ou temerosos das retaliações, possam procurar outros locais de trabalho. A necessidade de afastar-se da instituição na qual houve 
derrota eleitoral parece não ser característica apenas de Curitiba, tendo sido relatada por Castro (1998, p. 18) acerca do processo eleitoral em uma escola estadual de Belo Horizonte.

Weber trata a ciência como aquela que acompanha o desenvolvimento da racionalidade humana, por meio do domínio técnico - explicações lógicas e racionais - dos fenômenos da vida. Em "Ciência e Política: duas vocações", o autor distingue a ciência, como vocação, enquanto conhecimento e experiência científica, alicerçada na especialização, da política como vocação, cuja atividade, autônoma, tem a paixão e a vaidade como fortes elementos. Esta ciência e política, como vocações, são tipificadas à luz do Estado Moderno, no qual elementos como poder, legitimação, autoridade e verdade se fazem presentes. Este Estado é um agrupamento político, que se distingue dos demais ao deter o monopólio da violência legítima, dominação do homem sobre o homem. É o Estado que tem o "direito" à violência.

\begin{abstract}
A violência não é, evidentemente, o único instrumento de que se vale o Estado - não haja a respeito qualquer dúvida -, mas é seu instrumento específico. Em todos os tempos, os agrupamentos políticos mais diversos - a começar pela família - recorreram à violência física, tendo-a como instrumento normal do poder. Em nossa época, entretanto, devemos conceber o Estado contemporâneo como uma comunidade humana que, dentro dos limites de determinado território - a noção de território corresponde a um dos elementos essenciais do Estado - reivindica o monopólio do uso da violência física. (WEBER, 2011, p. 66-67, grifo nosso).
\end{abstract}

Falamos ainda que o Estado é um agrupamento político, para Weber. A política, neste sentido, é "o conjunto de esforços feitos com vistas a participar do poder ou a influenciar a divisão do poder, seja entre Estados, seja no interior de um único Estado" (WEBER, 2011, p. 67).

O conhecimento é o elemento central da política e da ciência como vocação, o que as mantém ao acesso de poucos. Das duas vocações derivam as éticas da convicção e da responsabilidade. $\mathrm{Na}$ ética da responsabilidade prepondera a ideia de manter o jogo "sendo jogado"; as consequências das decisões, nesta ética, são analisadas, uma vez que é mais importante o acordo entre os dois lados do que a convicção. Para o cientista, a resposta nunca será definitiva, sendo contraposta a todo momento. Assim, a ciência não tem a dizer sobre as questões últimas, ela descreve as formas de se atingir determinados fins, sem julgamento de valor, pois este está nas pessoas.

A ética da convicção, por sua vez, tem como elemento central a crença individual. Não equivale a ausência da responsabilidade, como pode parecer de antemão. Quem age sob a ética da convicção não consegue reconhecer em sua ação justificativa para determinados resultados contrários aos fins imaginados, e colocará sobre o outro a responsabilidade por essas 
consequências desagradáveis. "Parece, portanto, que é o problema da justificação dos meios pelo fim que, em geral, coloca em xeque a ética da convicção" (WEBER, 2011, p. 145). Para o autor, as duas éticas - da convicção e da responsabilidade - não se contrapõe, mas se somam e "em conjunto, formam o homem autêntico, isto é, um homem que pode aspirar à vocação política” (WEBER, 2011, p. 155).

No processo democrático no qual a instituição escolar pública afirma pautar-se ${ }^{3}$, a dominação racional-legal tem presença marcante. Sem as regras, não há democracia. Mesmo nas outras formas de dominação descritas por Weber, ao exercer o poder, há limites da regra. A história, a fé, a tradição e a regra têm influência sobre as pessoas para que haja dominação, poder e obediência. "Seja como for, cada vez que se propõe interrogação acerca dos fundamentos que "legitimam" a obediência, encontram-se, sempre e sem qualquer contestação, essas três formas “puras” que acabamos de indicar" (WEBER, 2011, p. 69).

A dominação, portanto, tem na carga de obediência sua constituição, uma vez que, se o sujeito duvida da tradição, do carisma ou da racionalização, tal dominação acaba. A obediência envolve uma disposição, acreditar em algo mitificando o dominador. Quanto maior a crença, mais obediência legítima, e mais dominação, sem qualquer forma de contestação.

Sobre isso, e à luz do que vemos na escola e na figura da direção escolar em sua relação com o grupo, algumas situações demonstram a posição mítica / de superioridade em que o(a) diretor(a) é colocado(a), que pode ser exemplificada com os presentes comprados por ocasião do aniversário da diretora ou do "dia do diretor de escola", mesmo que não a respeitem ou apreciem. Por que presentes apenas para o(a) diretor(a)? Se fosse pelo prazer de presentear, outros não deveriam receber também? Qual a intenção do presente, ou do bolo especialmente trazido para um lanche especial, ou dos "Parabéns" cantados por todos os estudantes no pátio? Quem toma à frente dessas iniciativas? Por que são aceitas por todos(as)? Por que sempre aconteceram? Por fazerem parte da relação de quem detém o poder com seus subalternos? Por que tais manifestações acontecem em algumas escolas e em outras não?

A base do que está em jogo é o poder, relacionada ao regime de governo da instituição escolar, sim, mas que não deixa de ser uma forma de dominação, uma vez que, para Weber, "todo régimen de gobierno necesita del dominio em alguna forma, pues para su desempeño

${ }^{3}$ A Constituição Federal de 1988 e a Lei de Diretrizes e Bases da Educação - LDB 9394/96 -, assim como demais legislação delas derivadas, imputam às instituições escolares sua constituição democrática, à luz da constituição do Estado Brasileiro em um Estado Democrático. Assim, Projetos Político-Pedagógicos das escolas, ao apresentar os conceitos que fundamentam seu funcionamento, proclamam a forma de gestão democrática, no município analisado. 
siempre se deben colocar en manos de alguien poderes imperativos" (WEBER, 2002, p. 701). $\mathrm{O}$ autor ainda acrescenta que $\mathrm{o}$

poder de mando puede tener una modesta apariencia y el jefe puede considerarse como un "servidor" de los dominados. Esto ocurre casi siempre en el llamado gobierno directamente democrático. [...] No obstante, por reducida que se ala esfera del poder, deberán siempre confiarse a algún funcionario ciertas facultades de mando, con lo cual su situación pasará insensiblemente de la simple administración a una auténtica y expresa jefatura (WEBER, 2002, p. 701, grifo nosso).

Nem sempre é este o fundamento da escola pública, ainda que, como uma pequena instituição que têm, no Estado do Paraná, um órgão colegiado - Conselho Escolar - como gestor, poderia corresponder a esta última descrição. Não obstante, o poder delegado ao chefe da repartição escolar, historicamente, a não qualificação e empoderamento das pessoas que compõe o colegiado gestor, e a presidência deste colegiado sob o poder de mando do chefe da própria repartição, acabam concentrando ainda mais poder sobre as equipes gestoras.

$\mathrm{Na}$ escola, não distinta de outras instituições, a dominação racional-legal é atestada pelos diplomas. Ao mesmo tempo, a crença na autoridade, o interesse e a legitimidade que envolvem as formas de dominação, misturam-se à necessidade na expressão do poder. Quando os diretores eram indicados, a relação autoritária com eles era comum, o que fez nascer o desejo por eleições como uma forma mais democrática de ocupar a função, que poderia "naturalmente" ter se refletido em toda a escola. No entanto, a mudança na forma de provimento da direção não altera a ação social e, tampouco, excluiria as formas de dominação típicas das relações humanas e políticas. Quem tem ou passou a ter um poder legitimado, pelas diversas fontes, terá influência sobre os demais, uma vez que a disputa pelo poder envolve a disputa pela posse de fontes de legitimação (WEBER, 2002) e a existência do poder e da dominação (ainda que não percebida como tal) pressupõe obediência.

Neste sentido, em que se diferem os papeis de presidência da República e da Direção Escolar? Porque para ambos não podemos defender que qualquer sujeito se candidate? Se, no topo da democracia, há um demagogo, quem deve presidir cada uma das instituições?

Devemos nos ater aqui à finalidade destes aparatos, destas instituições e das funções de quem se coloca no "topo", na direção. A Escola tem uma finalidade bastante evidente, induzindo a que tenhamos um sujeito, no topo de sua democracia, capaz de conduzir um processo político-pedagógico. Para a presidência da República, o caráter político sobressai-se ao técnico, uma vez que a estrutura ministerial e assessorias constituirão o caráter mais técnico. 
Aquele sujeito que estará no topo da organização escolar, precisa ter racionalidadelegalidade (reconhecimento de mérito), de forma democrática, de uma função que é também técnica. No entanto, como não é somente técnica, precisa ter outros atributos. A direção escolar compõe-se de burocratas da estrutura racional-legal, com atribuições técnicas; no entanto, na escola, instituição na qual as pessoas passam tanto tempo, há uma complexidade de interesses e disputas. Logo, a pessoa que coordena aquele processo coordena tais disputas, operando no campo da política.

Há várias formas de provimento para a função diretiva das escolas. A nomeação ou livre indicação, a consulta à comunidade, o concurso, para falar das mais conhecidas. A nomeação ou livre indicação considera apenas a natureza política da função, enquanto os concursos tomam em consideração apenas a característica técnica.

Sendo a função diretiva tencionada pela política, a junção das duas formas de provimento é aqui defendida: concurso (técnica) e eleição/consulta à comunidade (política), por meio da qual o sujeito comprova sua capacidade de dialogar, ouvir, mediar.

Isto posto, entende-se que a democracia pressupõe o domínio da regra, e, portanto, será sempre burocrática. A gestão democrática, assim, é um contínuo, um ponto de chegada que envolve muita disputa de poder e não elimina as formas de dominação.

Se, para Weber, a dominação envolve de alguma forma a "fé", a obediência, temos na escola relações de crença entre a comunidade de profissionais da educação e familiares e a direção escolar. Os dominados precisam acreditar em algo: tradição, magia, ato heroico ou na lei, no mérito.

Magali Castro analisa, em "Um estudo das relações de poder na escola pública de ensino Fundamental à luz de Weber e Bourdieu: do poder formal, impessoal e simbólico ao poder explícito", as

relações de poder em duas escolas públicas de periferia de Belo Horizonte, em dois momentos: na interação rotineira do dia-a-dia, quando é exercido o poder simbólico e, em determinados momentos, quando a luta por posições de poder ou pela imposição de idéias desvenda o poder, tornando-o manifesto e revelado (CASTRO, 1998, p. 9).

Ainda que não sejam assim tão dicotômicas as relações de poder na escola, pois são aqui entendidas como permeadas ora por uma ora por outra expressão de poder ou dominação, e não isoladamente em cada uma delas, dada a situação específica, a autora traz algumas importantes reflexões para auxiliar no entendimento da manutenção de poder na escola, ou, como enunciado no começo deste estudo, da construção de "carreiras em carreiras inexistentes". 
Castro (1998) apresenta análise que vai ao encontro deste entendimento, de que as relações na escola são, a bem da verdade, permeadas por diferentes interesses e, portanto, podem ser lidas sob diferentes olhares, como expressão de poder - simbólico, a partir de Bourdieu - ou como expressão de dominação ou uso da violência - Weber. Sobre as interações e relações entre os sujeitos da Instituição escolar, a autora afirma que,

[desde] o momento em que entram na escola até a hora da saída, são submetidos a uma série de regras para o exercício de suas atividades, as quais acatam, em sinal de conivência com a ordem estabelecida, mesmo que não se conformem muito com ela. Nesta rotina, os chefes colocam a responsabilidade pelas inconveniências das ordens que emitem sempre na autoridade mais distante (CASTRO, 1998, p. 13).

Ou ainda:

\begin{abstract}
Alguns momentos críticos, vividos pela Instituição, revelam todas as incompatibilidades e divergências entre os atores e desvendam o poder que, ao invés de existir em sua forma simbólica do dia-a-dia, torna-se manifesto e revelado, expressando-se nas lutas pela imposição de idéias, que não se travam mais nos bastidores, mas abertamente. Em tais lutas, o uso da força, o apelo à legitimidade jurídica, a utilização das situações e habilidades em benefício próprio e a influência social, política ou ideológica colocadas por Weber substituem o poder do dia-a-dia, ao mesmo tempo formal, impessoal e simbólico (CASTRO, 1998, p. 14-15).
\end{abstract}

A equipe diretiva da escola assume este lugar de poder e dominação na instituição escolar, frente à comunidade, nos processos eleitorais e o carrega no dia-a-dia da unidade. A formação das carreiras de "direção escolar", se assim as podemos denominar, pode-se dar por este lugar privilegiado assumido e pelo silenciamento deste poder desvelado, citado por Castro (1998). No entanto, também se constrói na própria crença dos dominados naquele dominador, que detém o conhecimento dos instrumentos legítimos e sabe utilizá-los, o que colocaria em maior evidência as tipificações Weberianas, diferentemente do que faz a autora supracitada.

Ao descrever as relações de poder no momento das eleições de diretores, Castro (1998) evidencia a formação de grupos adversários e de processos que ora podem ser saudáveis ora dolorosos. Nas palavras da autora, o processo é saudável quando os profissionais mantêm a disputa em "nível civilizado", mas pode ser doloroso e com consequências irremediáveis se "o poder, o salário e o prestígio que estão em jogo, aliados às rixas já existentes em estado de latência, aguardando o momento da eclosão, impedem [...] a vivência do aspecto positivo das eleições" (CASTRO, 1998, p. 17).

A constituição das "carreiras de direção de escola" pode ter suas raízes no desconhecimento de outras fontes de dominação no interior da escola. Castro afirma que 
Em meio às orientações de supervisores e administradores, à preocupação com o cumprimento dos programas, à frequência às reuniões constantes, à preparação de aulas e correção de trabalhos e ao atendimento aos pais de alunos, os professores recebem o reflexo e refletem as relações de poder existentes. Elementos-chave dos contatos da instituição, os professores têm muito mais poder dentro da escola do que podem, sequer, imaginar (CASTRO, 1998, p. 20).

A autora afirma ainda que

O estudo realizado nos permitiu concluir que o poder simbólico é vivenciado, no dia-a-dia das escolas, por atores que procuram transformar em capital simbólico as outras espécies de capital que possuem, no sentido de "ganhar" as pessoas, para poderem contar com elas: os administradores e especialistas, detentores de cargos de maior poder hierárquico e de maior capital cultural expresso em títulos escolares, transformam este capital em moedas de competência e habilidades que vão lhes permitir o exercício do poder simbólico na escola. Enquanto funcionários e colegas de serviço de seus subordinados, com quem dividem os bancos do ônibus ou com quem compartilham seu carro, utilizam, inconscientemente, suas qualidades pessoais e sua habilidade de relacionamento para ganhá-los como adeptos na luta velada pela imposição de idéias (CASTRO, 1998, p. 20).

Se lido a partir do referencial Weberiano e das tipificações por ele feitas, tal descrição dos administradores que possuem maior "capital cultural expresso em títulos escolares" poderia ser relacionada também ao domínio racional-legal que estes passam a exercer sobre os demais sujeitos na escola.

É importante, ainda, para elucidar a análise da constituição das carreiras em carreiras de direção que, na verdade, não existem no Quadro do funcionalismo público do município de Curitiba, falar sobre a legalidade da ação. Finatti (2016) afirma que as normativas tratavam de impedir infinitas reeleições em função exatamente igual, mas diferenciavam a função de direção da de vice-direção, possibilitando o que ficou conhecido na Rede Municipal de Ensino de Curitiba como "dobradinha" - profissionais assumiam na função de diretor(a), eram reeleitos na mesma função, e no terceiro pleito trocavam de lugar com seu(sua) vice para poder concorrer novamente, e assim consecutivamente, até completar mais de duas décadas em funções diretivas. Entende-se, no entanto, que tanto em uma como em outra função (direção e vicedireção), a pessoa ocupa posição de poder na escola, pois assume a Equipe Diretiva ${ }^{4}$. É, portanto, avanço, do ponto de vista democrático e da indução à rotatividade de pessoas na

${ }^{4}$ Diferentemente da Rede Estadual de Ensino do Paraná, por exemplo, ambas as funções devem cumprir jornada de 40 horas semanais na escola, na direção, e são afastadas da docência, por exemplo. Ou seja, tanto diretor(a) quanto vice-diretor(a) assumem integralmente a direção da unidade educacional, e são igualmente presentes na instituição e na divisão de tarefas diretivas. 
função, o entendimento da nova legislação (2014) que limita a uma reeleição na equipe diretiva, independentemente se diretora ou vice.

\section{Considerações finais}

Diante do que foi exposto, é possível afirmar que a tal "constituição da carreira na carreira inexistente" se deu por diferentes fatores, dentre os quais destacamos:

a) A legalidade da ação; nenhuma legislação que tratou das consultas à comunidade escolar para escolha de equipes diretivas impediu que as reeleições acontecessem;

b) Quem assume a função tendo ganhado uma eleição se destaca frente aos demais e passa, se já não o fazia anteriormente, a exercer algum tipo de dominação - seja ela carismática, tradicional ou racional-legal sobre a comunidade escolar;

c) Uma vez na função, os(as) profissionais adquirem outros conhecimentos específicos da administração escolar, o que os(as) distingue dos demais profíssionais da escola;

d) Quem passa a dominar a burocracia, passa a exercer maior domínio racionallegal sobre os demais, ampliando a "obediência";

e) Uma vez sob dominação de outrem, os dominados não questionam a autoridade. Quando o fazem, deixam a função de dominados e passam a disputar o poder e as fontes de legitimação;

f) Os dominadores fazem política, agem na política e tem o conhecimento técnico legitimado (por seu diploma, pelas ações que implementa e dão certo, etc.);

g) Os dominados assumem a função de "verdadeiros funcionários", descrita por Weber:

O verdadeiro funcionário [...] não deve fazer política exatamente devido a sua vocação: deve administrar, antes de tudo, de forma não partidária. Esse imperativo aplica-se igualmente aos ditos funcionários "políticos", ao menos oficialmente e na medida em que a "razão de Estado", isto é, os interesses vitais de ordem estabelecida não estão em jogo. Ele deve desempenhar sua missão sine ira et studio, "sem ressentimentos e sem preconceitos". Não deve, em consequência, fazer o que o homem político, seja o chefe, sejam seguidores, está compelido a fazer incessantemente e necessariamente, isto é, combater. Com efeito, tomar partido, lutar, apaixonar-se - ira et studio - são as características do homem político. E, antes de tudo, chefe político. A atividade deste último está subordinada a um princípio de responsabilidade totalmente estranho, e mesmo oposto, ao que norteia o funcionário. A honra do funcionário reside em sua capacidade de executar conscienciosamente uma ordem, sob responsabilidade de uma autoridade superior, ainda que desprezando a advertência - ela se obstine a seguir uma falsa via. O funcionário deve executar essa ordem como se ela correspondesse a suas 
próprias convicções. Sem essa disciplina moral, no mais elevado sentido do termo, e sem essa abnegação, toda a organização ruina (WEBER, 2011, p. 9697, grifo nosso).

Ainda que, na prática, a descrição acima nem sempre seja verdadeira, com todo(as) os(as) profissionais. Nas escolas, observa-se uma falsa obediência, no sentido de que o professor pode até não expor sua contrariedade em relação a determinadas normas, ou decisões, o que não o impede de fazer o que bem quer, sempre que pode;

h) Se a "honra do chefe político" está na responsabilidade pessoal pelo que faz, talvez nem todos os(as) profissionais da educação queiram tal responsabilidade; talvez não queiram tomar partido sobre as coisas;

i) Aquele que estabeleceu, ao longo da história da RME de Curitiba, uma carreira de "direção de escola", talvez aspire à vocação política Weberiana, uma vez que, para manterse tanto tempo "democraticamente" no poder, deve ter aprendido a equilibrar a ética da convicção e a ética da responsabilidade, constituindo-se no homem autêntico (WEBER, 2011), ao menos aos olhos da comunidade que passou a representar por décadas.

Por fim, vale destacar que os profissionais que constituíram carreira nesta função que deveria ser transitória, o fizeram com o consentimento da comunidade escolar - profissionais da educação (docentes e não docentes) estudantes e seus familiares. Assim, suas formas de dominação podem ter sido distintas para cada um dos segmentos que representa, como diretor(a) eleito(a). Ainda, se possuem, por natureza da função, aparato técnico e político para manter-se na função, constituem-se autoridade na unidade, que não será questionada a não ser que se rompa a rotina imposta, de alguma forma, e alguém se disponha a disputar as fontes de legitimação.

Se não houvesse possibilidade de se contrapor a quem está no poder, não haveria em nenhuma escola disputas acirradas e as funções diretivas teriam sido constituídas por um maior número de profissionais. Mas não o foram. Agora, acabadas as possibilidades de reeleição, uma vez que há uma restrição a essa possibilidade na atual legislação, quem irá se colocar na disputa? Como as atuais direções se colocarão, frente a não possibilidade de reeleições? Sairão de cena? Voltarão às salas de aula? Se aposentarão? Será que os atuais dominadores(as) farão seus herdeiros? 


\section{REFERÊNCIAS}

BRASIL. Constituição da República Federativa do Brasil de 1988. Brasília, DF: Presidência da República, 1988.

BRASIL. Lei n. 9394/96, de 20 de dezembro de 1996. Estabelece as diretrizes e bases da Educação Nacional. Diário Oficial da União: Seção 1, Brasília, DF: MEC, p. 27833, 23 dez. 1996. PL 1258/1988.

CASTRO, M. Um estudo das relações de poder na escola pública de ensino fundamental à luz de Weber e Bourdieu: do poder formal, impessoal e simbólico ao poder explícito. Rev. Fac. Educ., São Paulo, v. 24, n. 1, p. 9-22, jan. 1998. DOI: http://dx.doi.org/10.1590/S010225551998000100002

FINATTI, R. R. Eleições como forma de provimento da direção escolar na Rede Municipal de Ensino de Curitiba. Orientador: Ângelo Ricardo de Souza. 2016. 186 f. Dissertação (Mestrado em Educação) - Universidade Federal do Paraná, Curitiba, 2016.

WEBER, M. A "objetividade” do conhecimento nas ciências sociais. In: WEBER, M. Weber - coleção grandes cientistas sociais. São Paulo: Ática, 2003.

WEBER, M. Ciência e Política: duas vocações. Trad. Leonidas Hegenberg e Octany Silveira da Mota. 18. ed. São Paulo: Cultrix, 2011.

WEBER, M. Economia y Sociedad: esbozo de sociologia comprensiva. Trad. José Medina Echavarría, Juan Roura Parella, Eugenio Ímaz, Eduardo Garcia Máynez e José Ferrater Mora. Madrid: Fondo de Cultura Económica de España, 2002.

\section{Como referenciar este artigo}

FINATTI, R. R. Constituição de carreiras inexistentes, uma leitura a partir de Max Weber. Revista on line de Política e Gestão Educacional, Araraquara, v. 24, n. 3, p. 1445-1460, set./dez. 2020. e-ISSN:1519-9029. DOI: https://doi.org/10.22633/rpge.v24i3.13579

Submetido em: $15 / 04 / 2020$

Revisões requeridas: 06/06/2020

Aprovado em: 30/07/2020

Publicado em: 01/09/2020 